\title{
SIGNIFICADO DA FERIDA PARA PORTADORES DE ÚLCERAS CRÔNICAS
}

Maristela Oliveira Lara1 ${ }^{1}$ Assis do Carmo Pereira Júnior² ${ }^{2}$ Júlia Silva de Figueiredo Pinto ${ }^{3}$, Nayara Figueiredo Vieira ${ }^{4}$, Patrícia Wichr ${ }^{5}$

\begin{abstract}
RESUMO: Trata-se de um estudo descritivo, de abordagem qualitativa, com o objetivo de compreender o significado da ferida para portadores de úlceras crônicas. A coleta de dados foi realizada de janeiro a maio de 2010, por meio da entrevista individual a cinco pacientes e consulta aos prontuários dos pacientes atendidos durante o período de 2008 a 2010, em unidade ambulatorial. Para a análise dos dados utilizou-se a técnica da Análise de Conteúdo Temático que permitiu a identificação das categorias Sensações marcantes, O cotidiano e a ferida crônica e O impacto emocional. Os resultados demonstram que ser portador de úlcera representa conviver com a dor, preconceito, dependência para atividades diárias, receios, medos e ansiedade quanto ao prognóstico. Espera-se nortear os profissionais de saúde quanto às principais necessidades dessa clientela para elaboração de estratégias individualizadas a pacientes e cuidadores no manejo dos enfrentamentos vivenciados.
\end{abstract}

PALAVRAS-CHAVE: Úlcera; Adaptação; Percepção; Enfermagem.

\section{THE MEANING OF THE WOUND TO SUFFERERS OF CHRONIC ULCERS}

ABSTRACT: This descriptive study has a qualitative approach and aims to understand the meaning of the wound for patients with chronic ulcers. Data collection was carried out between January and May 2010, by means of individual interview with five patients and checking the medical records of patients attended during the period $2008-2010$ in a clinic unit. Analysis of the data was via thematic content analysis, which permitted the identification of the categories of outstanding sensations, daily routine, the chronic wound and the emotional impact. The results demonstrate that having a chronic ulcer means living with pain, prejudice, dependency on others for the carrying out of activities of daily living, worries, fears, and anxiety over the prognosis. The study hopes to orientate health professionals as to the principle needs of this clientele in order to elaborate individualized strategies for patients and cares to manage the experiences they confront. KEYWORDS: Ulcer; Adaptation; Perception; Nursing.

\section{SIGNIFICADO DE LA HERIDA PARA PORTADORES DE ÚLCERAS CRÓNICAS}

RESUMEN: Este es un estudio descriptivo, de abordaje cualitativo, cuyo objetivo fue comprender el significado de la herida para portadores de úlceras crónicas. Los datos fueron recogidos de enero a mayo de 2010, por medio de entrevista individual a cinco pacientes y consulta a los prontuarios de los pacientes atendidos durante el período de 2008 a 2010, en unidad clínica. Para el análisis de los datos, se ha utilizado la técnica del Análisis de Contenido Temático, que permitió la identificación de las categorías Sensaciones distintivas, El cotidiano y la herida crónica y El impacto emocional. Los resultados demuestran que ser portador de úlcera representa convivir con el dolor, prejuicio, dependencia para actividades diarias, miedos y ansiedad cuanto al prognóstico. Es importante orientar los profesionales de salud acerca de las principales necesidades de esa clientela para elaboración de estrategias individualizadas a pacientes y cuidadores en el tratamiento de los afrontamientos vividos.

PALABRAS-CLAVE: Úlcera; Adaptación; Percepción; Enfermería.

${ }^{1}$ Enfermeira. Mestre em Saúde e Enfermagem. Professora do Curso de Graduação em Enfermagem da Universidade Federal dos Vales do Jequitinhonha e Mucuri - UFVJM.

${ }^{2}$ Enfermeiro. Especialista em Saúde Coletiva. Professor Substituto do Curso de Graduação em Enfermagem da UFVJM.

${ }^{3}$ Enfermeira.

${ }^{4}$ Acadêmica de Enfermagem da UFVJM.

${ }^{5}$ Enfermeira. Mestre em Enfermagem. Professora do Curso de Graduação em Enfermagem da UFVJM. 


\section{INTRODUÇÃO}

Vivemos uma época de hipervalorização da estética e da beleza, em que a imagem corporal é relacionada à juventude, vigor, integridade e saúde. A sensação de transmitir imagem negativa aos outros e a falta de autoconfiança interferem nas relações sociais.

Algumas vezes, a presença de úlceras crônicas resulta em mudanças na aparência física, provocando diferentes reações em pacientes, amigos e familiares. Essas reações dependem da capacidade de adaptação dos envolvidos, do ritmo com que as alterações ocorrem e dos serviços de apoio disponíveis. Quando acontece uma transformação na imagem corporal, como por exemplo, na amputação, geralmente o paciente se ajusta às seguintes fases: estado de choque, recolhimento, reconhecimento, aceitação e reabilitação ${ }^{(1)}$. Desse modo, o tratamento das feridas crônicas requer, além de orientação científica adequada, a promoção de conforto emocional ${ }^{(2)}$.

Uma enfermidade crônica interfere nas adaptações da vida em andamento, ao fazer com que a realização de tarefas rotineiras se torne mais desafiadora. $\mathrm{O}$ meio social e o ambiente físico no qual o indivíduo vive podem afetar as capacidades, a motivação e a manutenção física da $\operatorname{pessoa}^{(1-2)}$. A ferida pode representar uma agressão à integridade, produzindo um desequilíbrio psíquico; também pode gerar, frequentemente, momentos de depressão que dificultam a realização de ações de autocuidado ${ }^{(3)}$.

As úlceras crônicas, atualmente chamadas de feridas complexas, são consideradas um problema de saúde pública. Elas contribuem para o aumento do número de aposentadorias precoces, fazendo com que haja perda de mão-de-obra ativa. A úlcera venosa, conhecida como lesão crônica de perna, não traz só sofrimento físico ao paciente, mas o impede de trabalhar, causando problemas socioeconômicos, tanto para o portador quanto para as organizações de saúde e a sociedade ${ }^{(4-5)}$. Os custos com o tratamento geralmente são altos e, na maioria das vezes, o cliente não consegue arcá-los.

Nesse contexto, as alterações provocadas pela ferida podem comprometer a qualidade de vida. Se não houver orientação adequada quanto ao tratamento ou o reconhecimento da importância das complicações que decorrem desta patologia, poderá haver prejuízos à satisfação na vida familiar, amorosa, social e à própria estética existencial ${ }^{(3-6)}$.

Conjugar uma doença crônica com a qualidade de vida tem sido um desafio entre os profissionais de saú- de, pessoas que vivenciam a doença e seus familiares. Muitas vezes, o profissional que presta assistência ao portador de uma ferida não dimensiona a interferência que esta lesão pode acarretar frente à nova condição de vida desse paciente ${ }^{(6)}$.

Sabe-se que o profissional de enfermagem possui um papel fundamental no que se refere ao cuidado holístico ao paciente, e desempenha um relevante trabalho ao tratar feridas, pois é responsável por acompanhar a evolução da lesão, orientar e executar o curativo de forma eficiente e humanizada. Como este profissional está diretamente relacionado ao tratamento de feridas, seja em serviços de atenção primária, secundária ou terciária, deve-se ressaltar a responsabilidade de manter a observação intensiva com relação aos fatores locais, sistêmicos, psicossociais e externos que condicionem o surgimento da ferida ou interfiram no processo de cicatrização. Portanto, é necessária uma visão clínica que relacione alguns pontos importantes que influenciam neste processo, como o controle de patologia de base presente (hipertensão arterial, diabetes mellitus), aspectos nutricionais, infecciosos, medicamentosos e, sobretudo, abordar o lado emocional de se possuir uma ferida crônica ${ }^{(5)}$.

A gênese desse estudo provém do acompanhamento de graduandos de Enfermagem em campo de estágio, na assistência a pacientes portadores de feridas crônicas, apresentando reações psicoemocionais e evidenciando enfrentamentos perante as limitações e consequências da ferida. A pesquisa teve como objetivo compreender o significado da ferida para os portadores de úlceras crônicas.

\section{METODOLOGIA}

A estratégia utilizada para a abordagem do tema desse estudo foi qualitativa. O tipo qualitativo de pesquisa aplica-se ao estudo da história, das relações, das representações, das crenças, das percepções e das opiniões, produtos das interpretações que os sujeitos sociais fazem a respeito de como vivem, constroem seus artefatos e a si mesmos, sentem e pensam. Essa estratégia, além de permitir desvelar processos sociais ainda pouco conhecidos, propicia a construção de novas abordagens, revisão e criação de novos conceitos e categorias durante a investigação ${ }^{(7)}$.

Trata-se de um estudo descritivo, ou seja, aquele que visa descrever características de determinada população ou fenômeno, ou o estabelecimento de relações entre as variáveis, que utiliza técnicas padronizadas de coleta de dados, entre elas, a entrevista ${ }^{(8)}$. 
O cenário dessa pesquisa foi a unidade ambulatorial de uma policlínica do interior de Minas Gerais no qual é desenvolvido o Programa de Extensão do Departamento de Enfermagem da Universidade Federal dos Vales Jequitinhonha e Mucuri (UFVJM), denominado Programa de Apoio ao Portador de Feridas, Derivação Intestinal e Urinária. O programa atende clientela específica, prestando assistência de enfermagem desde outubro de 2008.

Para a coleta de dados foram empregadas duas estratégias: a entrevista e a análise documental. As entrevistas individuais obedeceram a um roteiro semiestruturado, foram gravadas e transcritas na íntegra e realizadas com cinco usuário portadores de feridas crônicas que compareceram à unidade de saúde, no período de janeiro a maio de 2010, e atenderam aos seguintes critérios de inclusão: estar em tratamento no serviço de apoio ao portador de feridas e ser portador de lesão há, pelo menos, um ano. $\mathrm{O}$ número de entrevistados, idendificados como E1, E2, etc, atendeu ao critério de saturação de dados, que consiste no fechamento amostral por se considerar que o material obtido apresenta redundância ou repetição de dados ${ }^{(7)}$. A análise documental procedeu da consulta aos prontuários dos 55 pacientes participantes do referido programa; em 11 prontuários houve a identificação de registros relativos a alterações psicossociais e comportamentais em decorrência da ferida, as quais foram agregadas à análise.

Para a análise dos dados foi utilizada a técnica da Análise de Conteúdo Temático que permite a identificação das categorias a partir dos pressupostos teóricos e categorias empíricas, além de possibilitar a inferência de conhecimentos relativos às condições de produção/ recepção destas mensagens ${ }^{(9-10)}$.

A pesquisa foi aprovada pelo Comitê de Ética em Pesquisas da UFVJM, sob o protocolo n. 074/09, sendo realizada de acordo com a Resolução 196/96 do Conselho Nacional de Saúde para pesquisas com seres humanos, no que diz respeito ao sigilo, anonimato, consentimento livre e esclarecido e liberdade de desistir a qualquer momento da pesquisa.

\section{RESULTADOS}

Após a análise dos dados foram obtidas três categorias temáticas, apresentadas a seguir:

\section{Sensações marcantes}

A princípio os entrevistados mostraram dificuldade em descrever sua percepção sobre a ferida, apresen- tando com palavras o que sentiam como portadores de úlceras crônicas. Apesar disso, o cenário das sensações referidas foi constituído por dores, dificuldades, medos, esperanças e preconceitos sofridos por estes, como explicitado nos discursos a seguir:

[...] o que amola muito é a dor; dói muito a perna, dói muito [...]. É porque incomoda, incomoda dia e noite mesmo; é dor forte que queima. Tem dezoito anos que eu vivo sentindo dor direto. (E1)

Encosta na cama, dói; eu ponho o pé pra cima dói [...]. Essa noite eu quase não dormi, ela dói, coça. (E5)

Eu já sou muito discriminado por causa dessa ferida [...]. Já houve pessoa de falar, assim, que não poderia sentar no mesmo lugar que eu sentava, nem tão pouco comer nas vasilhas que eu usasse. (E4)

A discriminação referida extrapola para a desvalorização social do indivíduo, que se sente desestruturado, incapaz e segregado, enfrentando o preconceito como exemplificado nas seguintes expressões:

[...] se eu não tiver um determinado cuidado de verificar bem, não pôr mais faixas, mais gazes, aquilo ali começa a dar problema. Então eu tenho que logo desaparecer, senão todo mundo repara. (E4)

Determinada vez eu pedi pro médico um comprovante, porque os outros pensavam que isso era uma coisa [...] até hanseníase, que era lepra. (E2)

Nos prontuários analisados há um reforço da característica "dor" como fator de desconforto e que limita várias atividades diárias.

\section{O cotidiano e a ferida crônica}

Evidenciar o cotidiano do portador de ferida crônica possibilita abordar as limitações deste indivíduo que vão desde a dependência para realizar simples tarefas do cotidiano até a incapacidade de locomoção, sendo que muitos se declararam frágeis e desestimulados:

Ela [a ferida] atrasa a gente muito. A gente não consegue fazer quase nada, né? A gente não pode trabalhar. A gente tem que ficar quase de repouso, né? (E1)

Cada um reflete suas dificuldades no cotidiano de 
maneira diversa, seja por meio de crises de depressão, temor, pânico, seja com esperança e desejo de uma vida melhor, livre de tantas adversidades. Nos registros de atendimento encontramos, em todas as evoluções de enfermagem, descrição de ansiedade e desânimo do cliente em relação à terapia e ao prognóstico:

Eu, no meu caso mesmo, me sinto incapacitada para tudo. Eu não faço nada, fico agitada, fico nervosa, porque dói vinte e quatro horas. [...] minha dificuldade maior é porque eu preciso das minhas pernas. E ela [a dor] me tira toda a vontade de andar. (E3)

Eu ando muito devagar! Eu ando mais devagar do que qualquer pessoa [...]. (E4)

Até que agora eu ergui minha cabeça, porque já teve época de eu pensar que eu ia ficar aleijado. Já teve época de eu pegar até ferramenta para cortar minha perna, eu mesmo, de dor, de eu rolar no chão assim de dor, de eu pensar que talvez não teria solução para o meu problema. (E1)

Os entrevistados responderam que é limitante conviver com a lesão crônica, uma vez que ela traz dependência excessiva para realizar diversas atividades; um dos exemplos e a dificultade para a realização dos curativos, necessitando de pessoal e transporte disponíveis para tal.

A gente depende de tudo [...] a perna é dura, não dobra. Tem o curativo, se aqui não fizer, tenho que depender de outra pessoa para fazer para mim. (E5)

\section{O impacto emocional}

O desgaste emocional sofrido pelos participantes da pesquisa é explícito. Muitos afirmam que desequilíbrios estão presentes em várias situações, que vão desde a ansiedade e desânimo até a depressão:

Ah, não sei, não. Tenho medo de isso virar outras coisas! De perder o membro, essas coisas [...]. (E2)

Eu estou tomando muito antidepressivo. Tomo remédio demais para dor e fico esperando, cada dia eu fico esperando uma melhora. Ás vezes melhora, às vezes não. Ah, e tudo isso te deixa muito nervosa, que cada dia que você deita e pensa que está melhorando. As meninas me dão a maior força e tudo, mas tem horas que você vê que você está perdendo a força. Eu já cheguei a perder! (E3)

As estratégias buscadas pelos portadores de úlceras crônicas para minimizar os receios constam em seguir e confiar no tratamento. Esse estudo revelou que, apesar dos medos, todos os entrevistados preferem acreditar que as terapêuticas utilizadas e o acompanhamento surtirão efeito. A religiosidade é uma fonte de apoio:

Eu procuro sempre fazer os curativos e me distrair com alguma coisa, assim, não ficar preocupando muito com aquilo [...]. (E5)

[...] cada um tem sua cruz. Então, a gente tem que acreditar, acreditar que tenho capacidade, sou capaz, que eu vou vencer e Deus vai me ajudar e que eu vou vencer. (E1)

\section{DISCUSSÃO}

Desde muito tempo o ser humano busca compreender as causas da dor em busca da libertação desse agravo. As pessoas, de um modo geral, sabem o que é dor, no entanto, algumas vezes, é difícil descrevê-la, por ser uma experiência individual, com características próprias do organismo, associada à história, além do contexto no qual ela é percebida ${ }^{(11)}$.

De acordo com a Associação Internacional para Estudos da Dor, podemos definí-la como uma experiência sensorial e emocional desagradável, associada à lesão real ou potencial dos tecidos, ou descrita em termos de tais danos. Sendo uma experiência subjetiva e pessoal, a dor crônica é descrita como aquela que dura meses, anos, ou a vida toda, podendo haver ocorrências intermitentes que se caracterizam por períodos de dor, intercalados com outros dela isentos ${ }^{(12)}$.

A dor é o sintoma predominante na enunciação dos participantes desse estudo, os quais atribuem à ela um dos maiores desconfortos físicos e que interfere nas ações cotidianas. Ressalta-se que o paciente com ferida crônica sofre dor de caráter físico e emocional ${ }^{(12)}$.

A experiência dolorosa é evento muito mais amplo, não
se resumindo apenas à intensidade. As características da
dor também devem ser avaliadas, incluindo o seu início,
local, irradiação, periodicidade, tipo de dor, duração e
fatores desencadeantes. É importante observar as rea-
ções comportamentais e fisiológicas da dor, tais como:
expressão facial, inquietação, posicionamento protetor,
insônia, ansiedade, irritabilidade, sudorese, palidez,
taquicardia, taquipnéia, hipertensão, entre outros

O momento de acordar não é o mesmo para o portador de ferida crônica, principalmente porque há 
dificuldade para encontrar uma posição de conforto ao dormir. As dores são incessantes e existem preocupações com o odor da ferida e com a secreção liberada, além do fato de incomodar as pessoas próximas e resultar em dependência para várias atividades ${ }^{(6)}$.

O cotidiano dos portadores de ferida revela dificuldades de locomoção, citadas pela maioria dos entrevistados, podendo-se perceber que suas inquietações ultrapassam os limites da dor. O paciente com ferida crônica, além das dores que sente, mostra-se triste, desanimado, irritado. Diante disso, fica claro que a experiência do portador de ferida crônica não se restringe à existência de uma lesão cuja cicatrização é demorada, mas às diversas consequências e limitações que essa situação causa ${ }^{(13)}$.

A úlcera crônica impõe limitações de ordem física que variam de intensidade, porque geralmente estão relacionadas com o tipo de ferida e sua localização, tempo de existência da lesão, além de outros fatores. Essas limitações geram mudanças nas atividades realizadas pela pessoa. A interferência abrange todos os aspectos físicos possíveis, como andar, tomar banho, trabalhar, viajar e dormir.

As limitações físicas se tornam grandes empecilhos para manter o bom humor e a autoestima dos portadores de úlceras crônicas, porque dor e estresse estão intimamente relacionados: a dor aumenta o estresse e o estresse aumenta a dor ${ }^{(14)}$. Diante da sua cronicidade e da possibilidade de recidiva, em maior ou menor período de tempo, essas lesões podem gerar repercussões psicossociais aos pacientes, na medida em que podem provocar mudanças no estilo de vida, prolongar o tempo de afastamento do convívio social, provocar alteração da autoimagem, o que afeta diferenciadamente cada indivíduo, além de ser um limitante para o exercício de atividades diárias ${ }^{(15)}$.

É importante que os portadores de úlceras crônicas empreguem estratégias no amparo ao tratamento, utilizando os meios disponíveis, ou seja, ocupando seu tempo e seus pensamentos com atividades que possam contribuir para a autoconfiança. Atividades tais como arte e lazer poderiam agregar maior esperança ao tratamento. Além disso, o apoio dos familiares e amigos pode fazer com que os portadores de úlceras tenham em suas vidas os efeitos psicossociais minimizados.

Nesse contexto, surge o seguinte questionamento: Pode-se dizer que os clientes percebem a ferida e seu significado apenas pelas dificuldades que elas representam?

A maioria das pessoas nunca passou, por exemplo, pela experiência de ser portador de feridas crônicas ou sofreu amputações e ostomias. Por isso, não conseguem pensar na dimensão metafísica da lesão, que transcende o corpo físico e atinge o corpo imaterial, espiritual, interno ${ }^{(1)}$. As emoções são colaborativas tanto para uma ação terapêutica eficaz como ineficaz e também são mediações que ajudam a compreender os interesses do paciente e, a partir daí, programar uma assistência direcionada a suprir as necessidades individuais mediante uma visão holística ${ }^{(16)}$.

É preciso, portanto, aprender a valorizar os aspectos psicológicos do portador de feridas, salientando a importância de ajudá-lo a lidar com os seus receios. A integralidade da pele está diretamente relacionada à autoestima e à autoimagem, o que pode, algumas vezes, gerar situações de conflito e angústia, como no caso de portadores de feridas crônicas ${ }^{(2)}$.

Uma possível explicação para os sentimentos da pessoa mutilada ou deformada fisicamente, em função da presença de feridas, talvez seja encontrada no preconceito e na cultura construída pela sociedade contemporânea. O corpo é cultuado a todo custo, em uma busca constante pelo referencial de beleza ditado pela mídia escravagista - corpos belos, magros, íntegros e bem torneados - o que nem sempre é sinônimo de saúde e bem-estar. Qualquer desvio desse padrão é suficiente para que o corpo seja considerado diferente, estranho, fora da norma ${ }^{(3)}$. Entretanto, há momentos e situações em que, diante da referência de beleza ditado pela mídia, é preciso resistir e acreditar que é possível aceitar o diferente, fugir daquilo que foi previamente estabelecido, ou seja, incluir ao invés de excluir ${ }^{(2)}$.

Os efeitos do preconceito prejudicam o processo saúde-doença e têm sido bastante estudados pela psicologia quando associados ao processo de enfrentamento diante das situações adversas. Esse enfrentamento, tradução da expressão coping, é conceituado como o conjunto de estratégias utilizadas pelas pessoas para adaptar-se a circunstâncias adversas. Sua função é a de administração da situação estressora, ao invés de controle ou domínio da mesma. Os processos de coping pressupõem a noção de avaliação, ou seja, como o fenômeno é percebido, interpretado e cognitivamente representado na mente do indivíduo ${ }^{(13)}$.

As respostas ou estratégias de enfrentamento estão classificadas em duas categorias: enfrentamento focalizado no problema e enfrentamento focalizado na emoção. O primeiro baseia-se no manejo ou modificação do problema ou situação causadora de estresse, visando controlar ou lidar com a ameaça, o dano ou o desafio. O enfrentamento focalizado na emoção é o 
sistema baseado na regulação da resposta emocional causada pelo problema/estressor com o qual a pessoa se defronta. Não sendo estratégias necessariamente excludentes, elas podem ser ferramentas utilizadas simultaneamente para lidar com determinada situação estressora. Estudos têm identificado ainda outras estratégias de enfrentamento, como a busca de suporte social, religiosidade e distração ${ }^{(14)}$.

A necessidade de promoção de melhor qualidade de vida para o ser humano, demonstra, de maneira clara, a busca do indivíduo por estratégias de enfrentamento e a necessidade de manter a sua integridade física e mental, construída ao longo da vida. É pela imagem corporal, que o ser humano possui do seu próprio corpo, que ele mantém um equilíbrio interno enquanto interage com o mundo, uma vez que esse equilíbrio é responsável por promover uma identidade, influenciando no desenvolvimento de suas habilidades ${ }^{(3)}$.

\section{CONSIDERAÇÕES FINAIS}

De acordo com o estudo, a percepção do portador de úlceras crônicas traduz-se em dificuldades decorrentes do agravo pela dor, preconceito, dependência para atividades diárias e consequentes alterações no estado emocional.

Os pacientes consideram que o sentimento de dor impossibilita sua convivência em família, levando às noites sem descanso e dificuldades para deambulação, fatores que interferem desfavoravelmente na vida dessas pessoas. Frente à problemática, questiona-se as ações para o alívio da dor e a inclusão da abordagem psicológica para lidar com as questões perturbadoras decorrentes da situação estressora vivenciada por portadores de feridas crônicas. Neste contexto, é relevante refletir sobre a inserção e percepção do enfermeiro.

A compreensão da individualidade no enfretamento das adversidades da vida e, nesse caso, da lesão crônica, trará recursos necessários e fundamentais para que o profissional de saúde e de enfermagem ofereça atendimento holístico, cada vez mais humanizado.

Elaborar estratégias no amparo ao tratamento dessa clientela, preferencialmente que ocupem tempo e pensamentos com atividades que possa lhe imprimir autoconfiança, representa uma alternativa, e nesse contexto, arte e lazer poderiam agregar esperança ao tratamento. Além disso, o apoio dos familiares e amigos poderá minimizar o efeitos psicossociais aos portadores de úlceras.

Nesse sentido, esse estudo acredita contribuir para que profissionais de saúde e enfermagem compreendam as percepções dos portadores de feridas crônicas e forneçam subsídios aos enfrentamentos impostos pela enfermidade. Também se espera que ele desperte para o desenvolvimento de outros estudos sobre o tratamento de úlceras crônicas, visando a qualificação e humanização da assistência.

\section{REFERÊNCIAS}

1. Potter PA, Perry AG. Fundamentos de enfermagem. $6^{\text {a }}$ ed. Rio de Janeiro: Elsevier; 2008.

2. Silva RCL, Figueiredo NMA, Meireles IB. Feridas: fundamentos e atualizações em enfermagem. São Caetano do Sul: Yendis; 2007.

3. Pereira Júnior ADC, Henriques BD. The nursing care of the colostomy patient. Rev enferm UFPE On Line. [Internet] 2010;4(n.esp) [acesso em 21 abr 2011]. Disponível: http://www.ufpe.br/revistaenfermagem/ index.php/revista/article/view/751/pdf_71

4. Silva FAA, Freitas CHA, Jorge MSB, Moreira TMM, Alcântara MCM. Enfermagem em estomaterapia: cuidados clínicos ao portador de úlcera venosa. Rev Bras Enferm. 2009;62(6):889-93.

5. Martins DA, Souza AM. O perfil dos clientes portadores de úlcera varicosa cadastrados em programas de saúde pública. Cogitare Enferm. 2007;12(3):353-7.

6. Lucas LS, Martins JT, Robazzi, MLCC. Qualidade de vida dos portadores de ferida em membros inferiores: úlceras de perna. Cienc Enferm. 2008;14(1):43-52.

7. Morais GFCM, Oliveira SHS, Soares MJGO. Avaliação de feridas pelos enfermeiros de instituições hospitalares da rede pública. Texto \& Contexto Enferm. 2008;17(1):98-105.

8. Gil AC. Como elaborar projeto de pesquisa. 4a ed. São Paulo: Atlas; 2002.

9. Minayo MCS. O desafio do conhecimento: pesquisa qualitativa em saúde. $6^{\text {a }}$ ed. São Paulo: Hucitec; 2006.

10. Pedroso RA, Celich KLS. Dor: quinto sinal vital, um desafio para o cuidar em enfermagem. Texto \& Contexto Enferm. 2006;15(2):270-6.

11. Sanches LM, Boemer MR. O convívio com a dor: um enfoque existencial. Rev Esc Enferm USP. 2002;36(4):386-93. 
12. Antoniazzi AS, Dell'Aglio DD, Bandeira DR. O conceito de coping: uma revisão teórica. Estud Psicol. 1998;3(2):273-94.

13. Oliveira ECM, Poles K. Crenças do paciente com ferida crônica: uma analise discursiva. REME: Rev Min Enferm. 2006;10(4):354-60.

14. Oliveira SHS, Soares MJGO, Rocha OS. Uso de cobertura com colágeno e aloe vera no tratamento de ferida isquêmica: estudo de caso. Rev Esc Enferm USP. 2010;44(2):346-51.

15. Brito ES, Rabinovich EP. Desarrumou tudo! O impacto do acidente vascular encefálico na família. Saúde Soc. 2008;17(2):153-69.

16. Seidl EMF, Tróccoli BT, Zannon C.M.L.C. Análise fatorial de uma medida de estratégia de enfrentamento. Psic.: Teor. e Pesq. 2001;17(3):225-34. 